\title{
Autonomic Adjustments to Severe Hypotension in Fetal and Neonatal Sheep
}

\author{
ANNE MONIQUE NUYT, JEFFREY L. SEGAR, AARON T. HOLLEY, AND JEAN E. ROBILLARD \\ The Research Center Hopital Sainte-Justine, Department of Pediatrics, University of Montreal, Montreal, \\ Québec, Canada [A.M.N.]; Departments of Pediatrics and the Cardiovascular Center, College of \\ Medicine, University of Iowa, Iowa City, Iowa, U.S.A. [J.L.S., A.T.H.]; and Departments of Pediatrics, \\ School of Medicine, University of Michigan, Ann Harbor, Michigan, U.S.A. [J.E.R.]
}

\begin{abstract}
In fetal sheep, severe hypotension causes heart rate (HR) slowing. Studies during development have also shown that a reflex bradycardia and hypotension can be elicited after chemostimulation with veratridine and is dependent on the age of the animal. In adults, a vagally mediated depressor reflex characterized by bradycardia, hypotension, and withdrawal of efferent sympathetic activity can be observed after stimulation of chemosensitive or mechanosensitive cardiac receptors with veratridine or in circumstances of reduced cardiac filling. This reflex, known as the Bezold-Jarisch reflex, plays a role in disease states such as myocardial ischemia and hemorrhage. The objectives of our study were to determine whether a sympathoinhibitor depressor reflex, along with the bradycardia, is observed during pharmacologically induced hypotension in fetal and newborn lambs. In both fetal and newborn lambs, HR and renal sympathetic nerve activity (RSNA) initially increased $(p<0.05)$ in response to nitroprusside infusion to reach a maximum value. The range (or "plateau") of mean arterial blood pressure over which maximum RSNA was maintained constant before withdrawal of sympathetic tone started to be observed was significantly $(p<0.05)$ smaller in fetuses $(0.3$ $\pm 0.3 \mathrm{~mm} \mathrm{Hg})$ than newborn $(6 \pm 1 \mathrm{~mm} \mathrm{Hg})$ lambs. Similarly, the plateau over which maximum HR was maintained before onset of bradycardia was significantly smaller in fetuses ( $4 \pm 1$ versus $11 \pm$ $2 \mathrm{~mm} \mathrm{Hg}$ ). The mean arterial blood pressure level ("threshold") at
\end{abstract}

\section{ABSTRACT}

which a depressor reflex was triggered was significantly $(p<0.05)$ lower in fetal than newborn sheep ( $35 \pm 2$ versus $53 \pm 3 \mathrm{~mm} \mathrm{Hg}$ for $\mathrm{HR}$ and $35 \pm 2$ versus $57 \pm 2 \mathrm{~mm} \mathrm{Hg}$ for RSNA). The rates of fall (slopes) for both HR and RSNA were also significantly ( $p<$ $0.05)$ more pronounced in fetuses $(1.85 \pm 0.27$ and $6.08 \pm$ $2.45 \% / \mathrm{mm} \mathrm{Hg})$ than in newborns $(1.21 \pm 0.16$ and $1.97 \pm$ $0.32 \% / \mathrm{mm} \mathrm{Hg}$ ). Bilateral vagotomy significantly increased the plateau of mean arterial blood pressure over which maximum RSNA and HR were maintained constant. Vagotomy also decreased the threshold for both RSNA and HR and the slope of the RSNA response to the nitroprusside infusion in newborn lambs. Results from this study show that activation of the arterial baroreflex during nitroprusside-induced hypotension is followed by withdrawal of sympathetic tone and bradycardia and that this depressor reflex is more pronounced in late-gestation fetuses than newborn lambs and is significantly attenuated after bilateral vagotomy in newborn lambs. (Pediatr Res 49: 56-62, 2001)
AP, amniotic pressure
BJ, Bezold-Jarisch
HR, heart rate
MABP, mean arterial blood pressure
RSNA, renal sympathetic nerve activity

Abbreviations:
In fetal sheep, in contrast to the tachycardic response to moderate hypotension $(1,2)$, severe hypotension causes HR slowing (2-4). This reflex bradycardia can be observed in response to hemorrhage (2), vena caval obstruction $(5,6)$, and vasodilator infusion (7). In adults, hypotension and bradycardia can be elicited after stimulation of mechanical or chemosensitive left ventricular receptors, such as in circumstances not only

Received August 5, 1999; accepted August 9, 2000.

Correspondence and reprint requests: Jean E. Robillard, M.D., Department of Pediatrics, University of Michigan Hospital, 1500 Simpson Drive, MBP-D3202, Ann Arbor, MI 48109-0718, U.S.A.

Supported by the National Institutes of Health grants HL-14388, DK-38302, and DK-43961. J.L. Segar is supported by Clinical Investigator Development Award HL02865. A.M. Nuyt was supported by the Medical Research Council of Canada. of major increase in left ventricular end-diastolic pressure but also of reduced cardiac filling and increased inotropic activity (8-12), and after the administration of veratrum alkaloids $(13,14)$. When bradycardia and hypotension are observed after administration of veratrum alkaloids, the phenomenon is classically termed BJ reflex. This response is reflex in origin and mediated by stimulation of cardiac chemo- or mechanoreceptors with nonmyelinated afferent fibers traveling within the vagus [reviewed by Minisi and Thames (13) and Nganele and Hintze (14)]. The efferent part of the reflex appears to involve withdrawal of peripheral sympathetic outflow and stimulation of vagal efferent activity. In adults, this vagally mediated depressor reflex plays a role in hemodynamic responses to disease states (such as myocardial ischemia, aortic stenosis, and hemorrhage) $(12,15)$ and in vasovagal syncope $(15)$. 
Studies performed during early development have shown that the responses elicited after chemostimulation with veratridine are dependent on the age of the animal (16-18), resulting in a paradoxical increase in HR and blood pressure in preterm fetal lambs and eliciting the classic depressor reflex in term lambs.

The paradoxical slowing in HR observed in hypotensive fetal sheep mimics the vagally mediated depressor reflex response to rapid hemorrhage in adult. It is not known, however, whether in developing animals withdrawal of sympathetic tone is associated with the bradycardia and whether this reflex is vagally mediated. Therefore the objectives of our study were first to determine whether a BJ-like depressor reflex, in particular the sympathoinhibition component, accompanies severe hypotension during development. Second, we sought to characterize this reflex by comparing the hypotension-mediated bradycardia and sympathoinhibition observed in fetal and newborn lambs. The third objective was to evaluate whether this depressor reflex is vagally mediated early in life.

\section{METHODS}

Animals. Studies were performed in chronically instrumented near-term fetal sheep (131-137 d, term $145 \mathrm{~d}$ ) and newborn lambs (3-7 d of age). Pregnant ewes and newborn lambs of Dorset and Suffolk mixed breeding were obtained from a local source. The pregnant ewes and the newborn lambs with their mother were housed in individual pens. Gestational ages were based on the induced ovulation technique as previously described (19).

All surgical and experimental procedures were performed following the Guiding Principles in the Care and Use of Animals approved by the Council of the American Physiologic Society and governed by the Animal Care and Use Committee of the University of Iowa.

Surgical preparation. Anesthesia and surgery of the ewe and the fetus $(n=14)$ were conducted as previously described $(20,21)$. Briefly, the ewe was fasted for $24 \mathrm{~h}$ before surgery; anesthesia was induced with $12 \mathrm{mg} / \mathrm{kg}$ of thiopental sodium (Pentothal Sodium, Abbott Laboratories, North Chicago, IL, U.S.A.) and maintained with a mixture of halothane (1\%), oxygen $(33 \%)$, and nitrous oxide $(66 \%)$. Under sterile conditions, the uterus was opened over the fetal hindlimbs, and polyethylene catheters were placed bilaterally into the fetal femoral arteries and veins. A catheter was also secured in the amniotic cavity to record changes in AP.

The fetal left kidney, renal artery, and renal nerves were exposed through a flank incision. After a branch of the left renal nerve bundle was isolated, the nerve was slightly lifted from underlying tissues and placed onto platinum electrodes for recording of RSNA as previously described $(1,22)$. Function of the renal nerve was tested by audible monitoring of bursts of neural activity and by examining changes in oscilloscope tracings and activity bursts during bolus infusion of phenylephrine. When function was demonstrated, the electrodes were secured using SilGel (SilGel 601A and 601B, Wacker-Chemie, Munich, Germany) as previously described (22). A plastic-coated copper wire, used as a ground wire, was secured in the paravertebral muscle. Fetal skin incisions were closed in separate layers, and the fetus was returned to the uterus. Maternal incisions were closed in separate layers. All catheters and wires were exteriorized through a s.c. tunnel and placed in a cloth pouch on the ewe's flank.

Anesthesia and surgery in the newborn lambs $(\mathrm{n}=21)$ as well as the placement of the femoral catheters and electrodes on renal nerves were conducted in a similar manner (1). Catheters and electrode wires were tunneled s.c. and secured to the lamb's back using porous elastic bandages.

In a second group of newborn lambs $(n=7)$, in addition to the procedures described above, the vagus was identified bilaterally though a midline anterior cervical incision. A cotton umbilical tape was carefully placed around each nerve, tied loosely, and exteriorized. The skin incision was closed and the umbilical tape was sutured to the skin to prevent pulling and damage to the nerves until the experiment.

Ampicillin sodium (Wyeth-Ayerst Laboratories, Philadelphia, PA, U.S.A.) was administered intramuscularly before surgery to the newborn lamb $(0.5 \mathrm{~g})$ and the ewe $(2 \mathrm{~g})$ and into the amniotic cavity after surgery $(2 \mathrm{~g})$. After surgery, the pregnant ewes were returned to individual pens and allowed free access to food and water. The lambs were housed with their mothers and nursed adequately. The animals were allowed at least $24 \mathrm{~h}$ of recovery before the experiment.

Physiologic studies. Before the start of the experiments, the ewes were transferred to the laboratory in a small cart and placed inside a Faraday cage. The newborn lambs were placed in a supportive sling-frame assembly inside a Faraday cage. The animals were sedated with an i.v. bolus of diazepam (ewe, $10 \mathrm{mg}$; lamb, $0.3 \mathrm{mg} / \mathrm{kg}$; Valium, Elkins-Sinn, Cherry Hill, NJ, U.S.A.), then given an i.v. bolus injection of the paralytic agent vecuronium bromide $(0.1 \mathrm{mg} / \mathrm{kg}$, Norcuron, Organon, West Orange, NJ, U.S.A.), intubated, and ventilated to maintain arterial blood gas values similar to those obtained during spontaneous respiration as previously described (22). Supplemental oxygen was administered to maintain $\mathrm{PaO}_{2}>100 \mathrm{~mm}$ $\mathrm{Hg}$ to eliminate any potential stimulation of chemoreceptors. Vecuronium bromide $(0.1 \mathrm{mg} / \mathrm{kg}$ estimated weight) was also administered to the fetus. Muscular paralysis was necessary to eliminate muscle movements that interfere with nerve recording. Additional doses of vecuronium bromide $(0.05 \mathrm{mg} / \mathrm{kg})$ were administered when muscle movements were detected. Sedation with diazepam and paralysis have previously been shown to have no effect on HR, arterial pressure, or plasma catecholamine concentrations in lambs (22). During the experiments, a solution of $5 \%$ dextrose and $0.2 \%$ sodium chloride containing $30 \mathrm{mEq} / \mathrm{L}$ potassium chloride was given i.v. at a rate of $100 \mathrm{~mL} / \mathrm{kg} / \mathrm{d}$ to both fetal and newborn lambs and at a rate of $1.5 \mathrm{~mL} / \mathrm{kg} / \mathrm{h}$ to the pregnant ewes, as fluid maintenance requirements. After intubation, a 1-h stabilization period was allowed before the start of the experiment.

During each experiment, MABP, and AP in fetuses, was recorded continuously using Statham P23 Db pressure transducers (Spectramed Inc., Critical Care Division, Oxnard, CA, U.S.A.) and a Grass recorder (Grass Model 7 Polygraph, Grass Instruments Co., Quincy, MA, U.S.A.). Fetal MABP was corrected relative to concomitant AP. HR was monitored with 
a cardiotachometer triggered from the arterial pressure pulse waves. Before the start of each experiment, pressure transducers were placed and calibrated at the level of the heart of the studied animal.

For recording of RSNA, renal nerve electrodes and ground wires were attached to a high-impedance probe (HIP5, Grass Instruments), and the neural signal was amplified $(\times 50,000)$ and filtered (low, $30 \mathrm{~Hz}$; high, $3000 \mathrm{~Hz}$; P511, Grass Instruments). The output of the amplifier was channeled to a model 511A oscilloscope (Tektronix, Inc., Beaverton, OR, U.S.A.) for visual evaluation, routed to an audio amplifier/loudspeaker (model AM8 audio monitor, Grass Instruments) for aural evaluation, and integrated using a Grass voltage integrator. The amplified, filtered, and integrated neurogram, along with the raw neurogram, MABP, $\mathrm{HR}$, and $\mathrm{AP}$, was stored on videotape (Vetter 4000A PCM, Vetter Digital, Rebersburg, PA, U.S.A.), displayed on the recorder, and simultaneously recorded on-line to a 486/33 MHz computer via a Data Translator DT 2801 16-channel analog-to-digital conversion board using the software Labtech Notebook (version 7.2, Laboratory Technologies, Wilmington, MA, U.S.A.).

Experimental protocols. The first series of studies was designed to determine the presence of and to characterize developmental changes in bradycardia and sympathoinhibition triggered by progressive hypotension ( $n=21$ for newborn and $n=14$ for fetal sheep). After allowing $1 \mathrm{~h}$ for recovery after tracheal intubation, $0.5 \mathrm{~mL}$ of arterial blood was removed before the start of each experiment for determination of arterial $\mathrm{pH}$, blood gases $\left(\mathrm{Po}_{2}\right.$ and $\left.\mathrm{Pco}_{2}\right)$, and hematocrit. An i.v. infusion of nitroprusside (Nitropress, Abbott Laboratories; $5-40 \mu \mathrm{g} / \mathrm{kg} / \mathrm{min}$ ) was then begun using an Harvard infusion pump. The infusion continued for 1 to 5 min until decreases of HR and RSNA were observed. The infusion rate, started at the lowest dose, was increased by small steps when MABP had stabilized at a given infusion rate.

The second series of studies was designed to assess the role of vagal neural pathways in the expression of the sympathetic component of the depressor reflex in an additional group of newborn lambs $(n=7)$. After completing the first set of nitroprusside infusions as described above, the vagus nerves were cut bilaterally as follows: after superficial and deep local anesthesia of both sides of the neck with lidocaine 2\% (Abbott Laboratories), the skin incision sutures were removed, the vagus nerves gently pulled using the umbilical tapes previously placed around the nerves, infiltrated with lidocaine, and sectioned using a sterile scissors. After bilateral vagotomy, MABP was maintained at baseline level, if needed, with a phenylephrine infusion $(0.3-3 \mu \mathrm{g} / \mathrm{kg} / \mathrm{min})$. After a 2 -h recovery period, MABP and RSNA were recorded during a nitroprussideinduced hypotension, as described above.

After the completion of each experiment, integrated RSNA was normalized by subtracting the background noise level from recorded values. The portion of baseline noise level included in the nerve signal was assessed by completely inhibiting nerve activity using an i.v. administration of the ganglionic blocking agent tetraethylammonium bromide (TEA, $10 \mathrm{mg} / \mathrm{kg}$; Sigma Chemical Co., St. Louis, MO, U.S.A.) (22) or after sacrifice using a lethal dose of i.v. pentobarbital sodium.
Table 1. Fetal and newborn arterial blood values

\begin{tabular}{lcc}
\hline & $\begin{array}{c}\text { Fetus } \\
(n=14)\end{array}$ & $\begin{array}{c}\text { Newborn } \\
(n=21)\end{array}$ \\
\hline $\mathrm{pH}$ & $7.33 \pm 0.02$ & $7.35 \pm 0.01$ \\
$\mathrm{PCO}_{2}(\mathrm{~mm} \mathrm{Hg})$ & $39 \pm 2$ & $35 \pm 1$ \\
$\mathrm{Po}_{2}(\mathrm{~mm} \mathrm{Hg})$ & $24 \pm 2$ & $142 \pm 8^{*}$ \\
Hematocrit $(\%)$ & $33 \pm 1$ & $23 \pm 1^{*}$ \\
\hline
\end{tabular}

Values are means \pm SEM, $n=$ number of animals studied.

$* p<0.01$ compared with fetus.

Analytical procedures. Arterial blood for $\mathrm{pH}, \mathrm{Pco}_{2}$, and $\mathrm{Po}_{2}$ was collected anaerobically in heparinized syringes, and measurements were immediately determined using a BGH 1302 $\mathrm{pH} /$ blood gas analyzer (Instrumentation Laboratory, Lexington MA, U.S.A.). Hematocrit was determined in duplicate using a meter caliper. The volume of blood sampled was replaced immediately after collection using an equivalent volume of maternal blood.

Computation and data analysis. In the first series of studies, HR and integrated RSNA were normalized for each animal and expressed as the percentage of the maximal HR or integrated RSNA achieved during the infusion of nitroprusside. In the second series of studies, performed after vagotomy, HR and integrated RSNA were expressed as percentage of the maximal value obtained during control nitroprusside infusion (i.e. before vagotomy) for each animal. In response to progressive hypotension caused by the infusion of nitroprusside, HR and RSNA gradually increased to reach a maximum value; the ranges of MABP ("plateau," see Fig. 2) over which maximum HR and RSNA were maintained constant before bradycardia and withdrawal of sympathetic tone started to be observed were calculated, and the MABP values ("threshold," see Fig. 2) at which HR and RSNA start to decrease (end of plateaus) were recorded. The relationships between the rate of fall in MABP and HR or RSNA ("slope," see Fig. 2) were analyzed by linear regression (GraphPad Inplot version 4.03, GraphPad Software, San Diego, CA, U.S.A.).

Differences in arterial blood values, MABP, HR, and RSNA between fetal and newborn sheep were analyzed using unpaired $t$ test. Differences in the depressor reflex response variables (Fig. 2) between fetal and newborn sheep were also determined using unpaired $t$ test. Comparisons within each group of animals were performed using paired $t$ test. Differences were considered significant when two-tailed probability was $<0.05$. All results are expressed as mean \pm SEM.

Table 2. Fetal and newborn resting $M A B P, H R$, and $R S N A$

\begin{tabular}{lcc}
\hline & Fetus & Newborn \\
\hline MABP (mm Hg) & $45 \pm 2$ & $73 \pm 2^{*}$ \\
HR (bpm) & $172 \pm 8$ & $216 \pm 8^{*}$ \\
HR (\% of maximum) & $91 \pm 1$ & $89 \pm 2$ \\
RSNA (\% of maximum) & $58 \pm 7$ & $80 \pm 4^{*}$ \\
$n$ HR & 14 & 21 \\
RSNA & 9 & 18 \\
\hline
\end{tabular}

Values are means \pm SEM, $n=$ number of animals studied.

HR (\% of maximum) and RSNA (\% of maximum) represent baseline HR and RSNA expressed as percent of the maximum value achieved during the infusion of nitroprusside. $1 \mathrm{~mm} \mathrm{Hg}=133.3 \mathrm{~Pa}$.

$* p<0.01$ compared with fetus. 


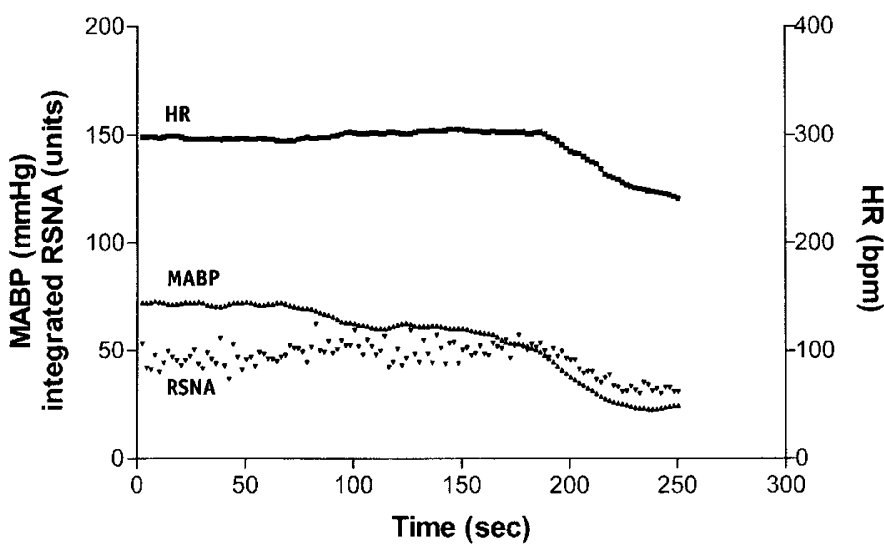

Fig. 1. Representative recording from a newborn illustrating the effects of changes in MABP on HR and RSNA as a function of time. Note initial increase in HR and RSNA as MABP progressively decreases, followed by a marked decrease in HR and RSNA, accompanied by a rapid decline in MABP.

\section{RESULTS}

Arterial blood gases and hematocrit. Arterial $\mathrm{pH}, \mathrm{PcO}_{2}, \mathrm{Po}_{2}$, and plasma hematocrit were within normal limits for both fetal $(n=14)$ and newborn lambs $(n=21)$ at the start of each experiment (Table 1). Arterial $\mathrm{Po}_{2}$ was significantly lower in fetal than in newborn lambs $(p<0.01)$, whereas plasma hematocrit was significantly higher $(p<0.01)$ in fetal than newborn lambs.

Baseline MABP, HR, and RSNA. Resting MABP and HR were significantly $(p<0.01)$ higher in newborn lambs than in fetal sheep (Table 2). When RSNA and HR were expressed as percent of the maximum value achieved during the infusion of nitroprusside, baseline RSNA was significantly $(p<0.01)$ higher in newborn lambs $(80 \pm 4 \%)$ than in fetal sheep $(58 \pm$ $7 \%$ ), although no difference in baseline HR was noted (newborn $89 \pm 2 \%$ and fetus $91 \pm 1 \%$ ).

Effect of nitroprusside-induced hypotension on $H R$ and $\boldsymbol{R S N A}$. A representative recording from a newborn lamb illustrating the effects of changes in MABP on HR and RSNA as a function of time is presented in Figure 1. During the nitroprusside infusion, HR and RSNA initially increased significantly in both fetuses (172 \pm 8 to $188 \pm 8 \mathrm{bpm}$ and $58 \pm 7 \%$ to $100 \%$
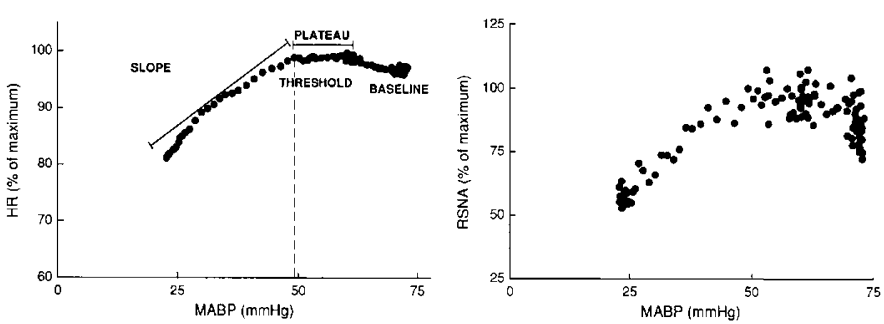

Fig. 2. Representative tracings of the response to progressive nitroprussideinduced hypotension in a newborn lamb for HR on the left and RSNA on the right. HR and RSNA are expressed as percent of maximal value achieved during the nitroprusside infusion. The plateau corresponds to a range of blood pressure at which maximum HR or RSNA is observed. The threshold corresponds to the blood pressure at which decreases in HR or RSNA start to be observed. The slope represents the relationship between changes in HR or RSNA and MABP. $1 \mathrm{~mm} \mathrm{Hg}=133.3 \mathrm{~Pa}$.
Table 3. Fetal and newborn depressor reflex variables for $H R$ and RSNA

\begin{tabular}{lcc}
\hline & Fetus & Newborn \\
\hline Plateau (mm Hg) & & \\
$\quad$ HR & $4 \pm 1$ & $11 \pm 2^{*}$ \\
RSNA & $0.3 \pm 0.3$ & $6 \pm 1^{*}$ \\
Threshold MABP (mm Hg) & & \\
$\quad$ HR & $35 \pm 2$ & $53 \pm 3^{*}$ \\
RSNA & $35 \pm 2$ & $57 \pm 2^{*}$ \\
Slope (\%/mm Hg) & $1.85 \pm 0.27$ & $1.21 \pm 0.16^{*}$ \\
$\quad$ HR & $6.08 \pm 2.45$ & $1.97 \pm 0.32^{*}$ \\
RSNA & 14 & 21 \\
$\quad$ HR & 9 & 18 \\
RSNA &
\end{tabular}

Values are means \pm SEM. $n=$ number of animals studied

$* p<0.05$ compared with fetus. The different components of the autonomic response to hypotension are defined in Figure 2.

of maximum RSNA, both $p<0.05)$ and newborn sheep $(216$ \pm 8 to $245 \pm 9 \mathrm{bpm}$ and $80 \pm 4 \%$ to $100 \%$ of maximum RSNA, both $p<0.05$ ).

The range of MABP over which maximum HR and RSNA were maintained constant (defined as "plateau," Fig. 2) before the depressor reflex was triggered was smaller in fetuses than in newborn lambs (Table 3 and Fig. 3). Similarly, the MABP level at which HR and RSNA started to decrease (defined as "threshold") was significantly lower in fetal than in newborn sheep (Table 3 and Fig. 3). The rate of fall ("slope," Fig. 2) for both HR and RSNA was also significantly more pronounced in fetuses than in newborns (Table 3 and Fig. 3).

Effect of vagotomy on BJ reflex in newborn lambs. In the presence of phenylephrine infusion, baseline MABP was not significantly different after vagotomy in newborn lambs (Table 4). A small but significant $(p=0.02)$ decrease in HR was observed after vagotomy (from $230 \pm 6$ to $208 \pm 5 \mathrm{bpm}$ ). Resting RSNA decreased significantly from $89 \pm 4 \%$ of maximal value achieved during the control nitroprusside infusion to $56 \pm 9 \%$ after vagotomy $(p=0.003)$.

During the progressive hypotension initiated by the infusion of nitroprusside, the plateaus at which RSNA and HR remained constant were significantly increased after vagotomy (RSNA, from $11 \pm 2$ to $28 \pm 3 \mathrm{~mm} \mathrm{Hg}, p<0.01$; HR, from $10 \pm 2$ to $27 \pm 3 \mathrm{~mm} \mathrm{Hg}$ ). The threshold triggering the depressor
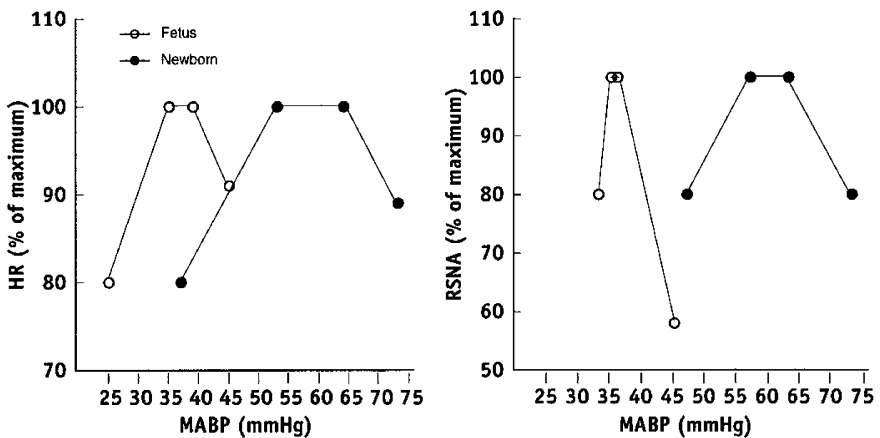

Fig. 3. Results obtained for HR on the left and RSNA on the right in response to progressive nitroprusside-induced hypotension in fetal and newborn sheep. HR and RSNA are expressed as percent of maximal value achieved during the nitroprusside infusion. Lines are generated from mean values as presented in Tables 2 and $3.1 \mathrm{~mm} \mathrm{Hg}=133.3 \mathrm{~Pa}$. 
Table 4. Newborn pre- and postvagotomy resting cardiovascular values and depressor reflex variables for HR and RSNA

\begin{tabular}{lcc}
\hline & Control & Postvagotomy \\
\hline Resting values $(n=7)$ & & \\
MABP (mm Hg) & $77 \pm 1$ & $76 \pm 1$ \\
HR (bpm) & $230 \pm 6$ & $208 \pm 5^{*}$ \\
HR (\% of maximum) & $91 \pm 2$ & $90 \pm 1$ \\
RSNA (\% of maximum) & $89 \pm 4$ & $56 \pm 9^{*}$ \\
Depressor reflex variables (number in parentheses $=n)$ & \\
Plateau (mm Hg) & $11 \pm 2$ & $28 \pm 3^{*}$ \\
$\quad$ RSNA (7) & $10 \pm 2$ & $27 \pm 3^{*}$ \\
HR (6) & $63 \pm 1$ & $44 \pm 2^{*}$ \\
Threshold MABP (mm Hg) & $54 \pm 2$ & $40 \pm 2^{*}$ \\
RSNA (7) & & \\
HR (6) & $1.537 \pm 0.14$ & $0.83 \pm 0.12^{*}$ \\
Slope (\%/mm Hg) & $1.05 \pm 0.14$ & $1.07 \pm 0.20$ \\
RSNA (6) &
\end{tabular}

The effect of vagotomy on the autonomic response to hypotension was studied in seven additional newborn lambs. Values are means \pm SEM.

$n=$ number of animals studied. $1 \mathrm{~mm} \mathrm{Hg}=133.3 \mathrm{~Pa}$.

$* p<0.05$ compared with control.

reflex was significantly lower after vagotomy for both RSNA and HR (RSNA, from $63 \pm 1$ to $44 \pm 3 \mathrm{~mm} \mathrm{Hg}, p<0.01$; HR, from $54 \pm 2$ to $40 \pm 2 \mathrm{~mm} \mathrm{Hg}, p<0.01$ ). In one animal, RSNA was maintained constant until MABP reached $35 \mathrm{~mm}$ $\mathrm{Hg}$, after which a prompt decrease occurred. For the remaining six animals, the RSNA/MABP slope was significantly reduced after vagotomy $(1.53 \pm 0.14$ to $0.83 \pm 0.12 \% / \mathrm{mm} \mathrm{Hg}, p<$ $0.01)$. The depressor reflex slope for HR was not changed after vagotomy $(1.05 \pm 0.14$ to $1.07 \pm 0.20 \% / \mathrm{mm} \mathrm{Hg})$.

\section{DISCUSSION}

The present study demonstrates that withdrawal of efferent sympathetic tone is associated with the reflex bradycardia triggered by severe hypotension during fetal and newborn life and characterizes the transition from an arterial baroreflexmediated response to a depressor response. Results from this study show that 1 ) accompanying nitroprusside-induced severe hypotension, bradycardia and withdrawal of sympathetic tone follow the initial arterial baroreflex-mediated response; 2) this depressor reflex is more pronounced in near-term fetal than newborn lambs; and 3) this reflex is significantly attenuated after bilateral cervical vagotomy in newborn lambs.

Nitroprusside, used in this study, reduces directly venous tone (23), therefore causing hypotension by reducing cardiac preload (24) and filling. Previous studies in sheep (2-4) have shown that fetal hemorrhage is associated first with an increase then with a rapid decrease in fetal HR as arterial blood pressure decreases further. However, in fetal animals, concomitant withdrawal of efferent sympathetic activity had never been documented. Similar results were also observed in newborn lambs (25) in which hypotensive hemorrhage resulted in a decreased RSNA. Taken together, these studies $(2-4,25)$ support the present results and indicate that reflex-mediated sympathoinhibition can be triggered by hypotension caused by reduced cardiac filling. In adults, stimulation of cardiac mechanoreceptors can elicit the vagally mediated BJ reflex characterized by bradycardia and withdrawal of sympathetic activity; results of the current study similarly support the presence of a functional $\mathrm{BJ}$ reflex during the perinatal period.

In the current study, the plateaus at which HR and RSNA are maintained at their maximal values are significantly increased in newborn compared with fetal lambs. The thresholds, or MABP value at which bradycardia and withdrawal of efferent sympathetic activity are first observed, are significantly lower in fetal than newborn lambs. Although this study was not designed to evaluate the factors regulating the developmental changes in plateau and threshold, one may speculate based on previous studies in adults (26) that increased activity of the renin-angiotensin system during the newborn period played a role in the prolongation of the plateau by supporting peripheral resistance for a longer period during hypotension. The agerelated increase in the threshold is likely also related to the increase in baseline MABP and resetting of the range over which MABP is maintained toward higher pressures, both occurring soon after birth (1). The mechanisms of these early neonatal cardiovascular resettings are only partly understood $(27,28)$.

The plateau and threshold also represent the transition from the arterial baroreflex-mediated increase in HR and RSNA to the activation of the depressor BJ-like reflex. The antagonism between the arterial baroreflex and the BJ reflex has been evidenced by adult animal studies reporting that chemo- and mechanoreceptor input from the left ventricle can inhibit the expression of the arterial baroreflex control of both HR and peripheral resistance during hypotension $(29,30)$. Interestingly, in anesthetized rats, blockade or attenuation of the BJ reflex by glutamate or $\gamma$-aminobutyric acid antagonist injected into the nucleus tractus solitarii, caudal ventrolateral medulla, and rostral ventrolateral medulla is associated with a concomitant blockade or attenuation of the arterial baroreflex, suggesting that the central pathway of the BJ reflex elicited by chemostimulation appears very similar to that of the arterial baroreflex (31). Based on these studies, we therefore speculated that the mechanisms regulating the developmental changes in the arterial baroreflex may also modulate the differences in the depressor reflex plateau and threshold between fetal and newborn life, the resulting effect being that in fetal life, the depressor reflex overrides the arterial baroreflex sooner in the hypotensive process than in the newborn period or that the arterial baroreflex is more potent in newborns.

The present study also demonstrates that the rate of decline (slope) of RSNA and of HR triggered by severe hypotension is more pronounced in fetal than newborn lambs. The significance of this is unclear inasmuch as vasomotor tone is mediated by neural and nonneural mechanisms. Nonetheless, it is evident that once the threshold pressure is reached, there is a rapid withdrawal of sympathetic tone, which contributes to further decreases in MABP. Factors regulating these differences were not investigated. However, studies in adult animals have suggested that prostaglandins (32), vasopressin (33), and angiotensin II (26) play an important role in modulating the BJ reflex response. Because prostacyclin activates the BJ reflex in adults $(14,32)$, we hypothesize that the presence of high levels of prostacyclin early in life (34) sensitize the BJ reflex. On the other hand, we speculate that the increased activity of the 
renin-angiotensin system after birth (35) may inhibit the BJ reflex response in the newborn lambs, as previously described in adults (26).

In the current studies, vagotomy significantly delayed the appearance of the depressor reflex in newborn lambs. During progressive hypotension, the RSNA threshold was shifted to the left toward lower blood pressure when compared with the intact state (prevagotomy). Moreover, the degree of the efferent sympathetic withdrawal, as measured by the slope of the RSNA/MABP relationship, was significantly reduced after vagotomy. Consistent with the present results, vagotomy also inhibits the decrease in RSNA observed during hypotensive hemorrhage in 3- to 7-d-old lambs (25), indicating that the afferent signal resulting in withdrawal of sympathetic tone travels at least in part through vagal afferents, as previously shown in adult BJ reflex studies $(12,36-38)$. In view of these data, we conclude that a significant proportion of the sympathoinhibitory response to severe hypotension in newborn sheep corresponds to a BJ reflex. Similarly to RSNA, HR threshold was significantly lower after vagotomy, and the plateau longer. The slope of the HR/MABP relationship was not significantly different after vagotomy, suggesting that in the newborn, there is also an efferent vagal component to this reflex. The HR response to the infusion of nitroprusside after vagotomy is difficult to interpret because the $\mathrm{BJ}$ reflex-induced bradycardia is indeed mediated in part by vagal efferents, being attenuated by muscarinic blockade $(12,39)$. Therefore, the HR response after vagotomy must be influenced by either withdrawal of cardiac sympathetic tone or circulating neurohumoral factors.

The fact that vagotomy did not completely abolish the presence of the depressor reflex indicates that pathways other than vagal afferents are involved in the response to severe hypotension. Indeed, sinoaortic denervation attenuates the decreases in fetal HR and the increases in neurohumoral factors observed after venocaval obstruction in fetal lambs (5). Tissue hypoperfusion and secondary changes in cellular oxygen level in central cardiovascular regulating areas could also be involved.

However, the current results contrast with studies $(16,18)$ in which stimulation of chemoreceptors with veratrum alkaloids did not elicit a BJ reflex in fetal lambs of similar gestational age and newborn piglets. The differences between the present results and previous studies using veratridine $(16-18)$ may be explained by the fact that chemo- and mechanoreceptors represent two separate populations of receptors, as previously shown in adult animals $(11,13,40)$. Furthermore, we speculate that the maturation of cardiac mechanoreceptors precedes the functional development of cardiac chemoreceptors. Little is known about the maturation of left ventricular receptors. Although in our study vagotomy significantly attenuates the depressor reflex caused by hypotension, it did not modify the excitatory response to veratridine in near-term fetal lambs (18), suggesting that the response to veratridine was not vagally mediated. In fact, the excitatory response to veratridine was inhibited by propranolol (18), suggesting a sympatheticmediated response (40) or a direct effect of veratridine on the release of catecholamines (41). These data are in favor of a differential maturation of the two types of ventricular receptors in their ability to stimulate the BJ reflex or in the development of their afferent pathways to the brain. The differences between the central pathways of the BJ reflex triggered by mechanoand chemostimulation still need to be investigated.

In summary, the present study demonstrates that a depressor reflex characterized by withdrawal of sympathetic tone and bradycardia can be triggered by severe hypotension during fetal and neonatal life and that in newborn lambs this response is in part mediated by an afferent signal traveling through the vagus. This depressor reflex operates at lower arterial pressures in fetal than in newborn lambs and is less pronounced after the transition from fetal to newborn life. The MABP over which HR and RSNA arterial baroreflex-mediated increases are maintained is prolonged in newborns.

\section{REFERENCES}

1. Segar JL, Hajduczok G, Smith FG, Merrill DC, Robillard JE 1992 Ontogeny of baroreflex control of renal sympathetic nerve activity and heart rate. Am J Physiol 263:H1819-H1826

2. MacDonald AA, Rose J, Heymann MA, Rudolph AM 1980 Heart rate response of fetal and adult sheep to hemorrhage stress. Am J Physiol 239:H789-H793

3. Kwan E, Rurak DW, Taylor SM 1995 Oxygen consumption, acid-base status, and behavior during and after acute, severe hemorrhage in fetal lambs. Am J Physiol 269:R758-R766

4. Meyers RL, Paulick RP, Rudolph CD, Rudolph AM 1991 Cardiovascular responses to acute, severe haemorrhage in fetal sheep. J Dev Physiol 15:189-197

5. Wood CE 1989 Sinoaortic denervation attenuates the reflex responses to hypotension in fetal sheep. Am J Physiol 256:R1103-R1110

6. Wood CE, Keil LC, Rudolph AM 1982 Hormonal and hemodynamic responses to vena caval obstruction in fetal sheep. Am J Physiol 243:E278-E286

7. Wood CE $1986 \mathrm{ACTH}$, cortisol and renin responses to arterial hypotension in sheep. Am J Physiol 251:R18-R22

8. Mark AL, Kioschos JM, Abboud FM, Heistad DD, Schmid PG 1973 Abnormal vascular responses to exercise in patients with aortic stenosis. J Clin Invest 52:11381146

9. Oberg B, Thoren P 1972 Increased activity in left ventricular receptors during hemorrhage or occlusion of caval veins in the cat - a possible cause of the vaso-vagal reaction. Acta Physiol Scand 85:164-173

10. Gupta BN, Thames MD 1983 Behavior of left ventricular mechanoreceptors with myelinated and nonmyelinated afferent vagal fibers in cats. Circ Res 52:291-301

11. Zucker IH 1986 Left ventricular receptors: physiological controllers or pathological curiosities? Basic Res Cardiol 81:539-557

12. Oberg B, White S 1970 The role of vagal cardiac nerves and arterial baroreceptors in the circulatory adjustments to hemorrhage in the cat. Acta Physiol Scand 80:395-403

13. Minisi AJ, Thames MD 1991 Reflexes from ventricular receptors with vagal afferents. In: Zucker IH, Gilmore JP (eds) Reflex Control of the Circulation. CRC Press, Boca Raton, FL, pp 359-405

14. Nganele DM, Hintze TH 1991 Cardiac preload control: an important function of cardiac chemical receptors. In: Zucker IH, Gilmore JP (eds) Reflex Control of the Circulation. CRC Press, Boca Raton, FL, pp 407-433

15. Mark AL 1983 The Bezold-Jarisch reflex revisited: clinical implications of inhibitory reflexes originating in the heart. J Am Coll Cardiol 1:90-102

16. Gootman PM, Buckley BJ, DiRusso SM, Gootman N, Yao AC, Pierce PE, Griswold PG, Epstein MD, Cohen HL, Nudel DB 1986 Age-related responses to stimulation of cardiopulmonary receptors in swine. Am J Physiol 251:H748-H755

17. Nuwayhid B, Brinkman CR, Su C, Bevan JA, Assali NS 1975 Development of autonomic control of fetal circulation. Am J Physiol 228:337-344

18. Anderson PAW, Fair EC, Nassar R, Gorman AJ, Killam AP 1994 A hemodynamic excitatory response to veratridine in the in utero lamb. Pediatr Res 35:550-554

19. Jennings JJ, Crowley JP 1972 The influence of mating management on fertility in ewes following progesterone-PMS treatment. Vet Rec 90:495-498

20. Robillard JE, Weitzman RE 1980 Developmental aspects of the fetal renal response to exogenous arginine vasopressin. Am J Physiol 238:F407-F414

21. Robillard JE, Nakamura KT, DiBona GF 1986 Effects of renal denervation on renal responses to hypoxemia in fetal lambs. Am J Physiol 250:F294-F301

22. Smith FG, Klinkefus JM, Kopp UC, Robillard JE 1990 Novel recordings of renal sympathetic nerve activity in conscious fetal sheep and newborn lambs. Am J Physiol 258:F218-F221

23. Mackenzie JE, Parratt JR 1977 Comparative effects of glyceryl trinitrate on venous and arterial smooth muscle in vitro: relevance to antianginal activity. $\mathrm{Br} \mathrm{J}$ Pharmacol 60:155-160

24. Vatner SF, Pagani M, Rutherford JD, Millard RW, Manders WT 1978 Effects of nitroglycerin on cardiac function and regional blood flow distribution in conscious dogs. Am J Physiol 234:H244-H252 
25. O’Mara MS, Merrill DC, McWeeny OJ, Robillard JE 1995 Ontogeny and regulation of arterial and cardiopulmonary baroreflex control of renal sympathetic nerve activity in response to nonhypotensive and hypotensive hemorrhage postnatally. Pediatr Res 37:31A(abstr)

26. Schadt JC, Ludbrook J 1991 Hemodynamic and neurohumoral responses to acute hypovolemia in conscious mammals. Am J Physiol 260:H305-H318

27. Segar JL, Merrill DC, Robillard JE 1994 Role of endogenous angiotensin II on resetting of the arterial baroreflex during development. Am J Physiol 266:H52-H59

28. Mazursky JE, Segar JL, Nuyt AM, Smith BA, Robillard JE 1996 Regulation of renal sympathetic nerve activity at birth. Am J Physiol 270:R86-R93

29. Holmberg MJ, Gorman AJ, Cornish KG, Zucker IH 1983 Attenuation of arterial baroreflex control of heart rate by left ventricular receptor stimulation in the conscious dog. Circ Res 52:597-607

30. Holmberg MJ, Zucker IH 1986 Increased left ventricular pressure attenuates the baroreflex in unanesthetized dogs. Am J Physiol 251:R23-R31

31. Verberne AJM, Guyenet PG 1992 Medullary pathway of the Bezold-Jarisch reflex in the rat. Am J Physiol 263:R1195-R1202

32. Hintze TH 1987 Reflex regulation of the circulation after stimulation of cardiac receptors by prostaglandins. Fed Proc 46:73-80
33. Barazanji MW, Cornish KG 1989 Vasopressin potentiates ventricular and arterial reflexes in the conscious nonhuman primate. Am J Physiol 256:H1546-H1552

34. Nuyt AM, Holley AT, Chemtob S, Chapleau MW, Segar JL, Robillard JE 1996 Role of endogenous prostaglandins in the regulation of arterial baroreceptor activity during development. Pediatr Res 39:234A(abstr)

35. Robillard JE, Weismann DN, Gomez RA, Ayres NA, Lawton WJ, VanOrden DE 1983 Renal and adrenal responses to converting-enzyme inhibition in fetal and newborn life. Am J Physiol 244:R249-R256

36. Skoog P, Mansson J, Thoren PN 1985 Changes in renal sympathetic outflow during hypotensive haemorrhage in rats. Acta Physiol Scand 125:655-660

37. Morgan DA, Thoren PN, Wilczynski EA, Victor RG, Mark AL 1988 Serotonergic mechanisms mediate renal sympathoinhibition during severe hemorrhage in rats. Am J Physiol 255:H496-H502

38. Evans RG, Ludbrook J, Ventura S 1994 Role of vagal afferents in the haemodynamic response to acute central hypovolaemia in unanaesthetized rabbits. J Auton Nerv Syst 46:251-260

39. Zucker IH, Cornish KG 1981 The Bezold-Jarisch reflex in the conscious dog. Circ Res 49:940-948

40. Hainsworth R 1991 Reflexes from the heart. Physiol Rev 71:617-658

41. Kirpekar M, Prat JC 1979 Release of catecholamines from perfused cat adrenal gland by veratridine. Proc Natl Acad Sci USA 76:2081-2083 